Research Article

\title{
Girder Longitudinal Movement and Its Factors of Suspension Bridge under Vehicle Load
}

\author{
Guoping Huang $\mathbb{D}^{1,2}$ Jianhua Hu $\mathbb{D}^{1,3}$ Haibo Liu, ${ }^{3}$ and Xiugui Sun ${ }^{1,4}$ \\ ${ }^{1}$ Key Laboratory for Wind and Bridge Engineering of Hunan Province, College of Civil Engineering, Hunan University, \\ Changsha 410082, China \\ ${ }^{2}$ College of Civil Engineering, Hunan City University, Yiyang 413000, China \\ ${ }^{3}$ Hunan Communication \& Water Conservancy Group Ltd., Changsha 410008, China \\ ${ }^{4}$ Hunan Provincial Communications Planning Survey \& Design Istute Co, Ltd., Changsha 410200, China
}

Correspondence should be addressed to Guoping Huang; gphuang@hnu.edu.cn

Received 6 August 2021; Accepted 9 September 2021; Published 1 October 2021

Academic Editor: Zhiyong Chen

Copyright (c) 2021 Guoping Huang et al. This is an open access article distributed under the Creative Commons Attribution License, which permits unrestricted use, distribution, and reproduction in any medium, provided the original work is properly cited.

\begin{abstract}
Vehicle load may not only cause vertical deformation and vibration of suspension bridge but also lead to longitudinal deformation and vibration. And the longitudinal behavior is closely related to the durability of the girder end devices and the bending fatigue failure of suspenders. In this study, the longitudinal deformation behavior and longitudinal vibration of suspension bridge under vehicles, as well as the related influencing factors, are investigated. The underlying mechanism of girder longitudinal movement under the moving vehicles is revealed. Based on the simplified vehicle model of vertical concentrated force, the characteristics of main cable deformation and girder longitudinal displacement under vertical loads are analyzed first. Then, the longitudinal motion equation of the girder under vertical moving loads is derived. Finally, a single long-span suspension bridge is employed in the case study, and the girder longitudinal response and influencing factors are investigated based on both numerical simulation and field monitoring. Results indicate that the asymmetric vertical load leads to cable longitudinal deflection owing to the geometrically nonlinear characteristic of the main cable, leading to longitudinal movement of the girder. The results of field monitoring and numerical simulation indicate that the girder moves quasi-statically and reciprocates longitudinally with centimeter amplitude under normal operational loads.
\end{abstract}

\section{Introduction}

The suspension bridge with great spanning ability is increasingly used in projects of spanning grand Canyons, seas, and islands [1]. However, such bridges are flexible and vibration sensitive, and the stiffness and vibration of the suspension bridges are major topics in research on structural dynamics. The previous studies showed that the fatigue and durability of girder end ancillary facilities such as the expansion joints, dampers, and bearing are related to the reciprocating longitudinal movement characteristics of the stiffening girders. The huge accumulative displacement caused by traffic or wind loads during the operational stage is an important reason for the damage of the end attached facilities [2-5]. The reciprocating longitudinal movement may also induce fatigue failure of short suspenders for suspension bridge [6-9] and oil leakage of hydraulic damper [10]. Meanwhile, the vehicle load can cause excessive rotation angle to the girder ends, which will affect driving safety and comfort $[11,12]$.

In early studies concerning girder end displacement and girder longitudinal vibration for the suspension bridges, majority of researchers were concerned with overlarge girder end displacement or pounding between adjacent components at the girder ends of the bridge [13-15]. However, for vehicle load, related to vertical moving loads, vertical vibration and deflection are directly and mostly investigated [16-19]. The longitudinal vibration caused by vehicles only 
involves the braking force, which is the longitudinal load excitation applied to the $\operatorname{deck}[14,20]$. The longitudinal response of the girder caused by earthquake is much larger than that caused by vehicle load, and the longitudinal vibration and control under operational actions were relatively less concerned.

An increasing number of investigators are paying attention to the issues of girder longitudinal movement and its factors under vehicle load for the suspension bridge at present, owing to increasing cases that the girder end devices fail prematurely due to operational actions. The vehiclegirder longitudinal movement relationship is mainly investigated qualitatively via statistical regression based on bridge health monitoring data [21-25], or numerical analysis based on finite element (FE) [26-28]. For example, Guo et al. [22] utilized the long-term monitoring data of two long-span suspension bridges and a long-span cable-stayed bridge in China to comparatively investigate the response characteristics of girder longitudinal movements. Sun et al. [23] also utilized the long-term monitoring data to evaluate the condition of girder end expansion joints for suspension bridge during the operational stage. $\mathrm{Hu}$ et al. [24] further investigated the frequency spectrum of longitudinal girder end displacement and quantitative contribution of longitudinal girder end cumulative displacement due to various load excitations.

Scholars also used the FE to analyze longitudinal vibration and control for the suspension bridges. For instance, Zhao et al. [26] established a bridge FE model to investigate the dynamic response of suspension bridge under random traffic load and influence of fluid viscous damper. Gao et al. [28] developed two bridge FE models to simulate interaction of traffic excitations and suspension bridges for evaluating the effect of the rigid central clamps on the longitudinal deformation of suspension bridges. However, the abovementioned investigation ignored the underlying mechanical mechanism on longitudinal behavior of suspension bridges under vehicle load, which is often covered by huge monitoring data and numerical analysis.

This study is devoted to investigating the longitudinal deformation and vibration of suspension bridge under traffic loads by combining field measurement, theory analysis, and numerical simulation with two specific aims: (1) to reveal the underlying mechanisms of girder longitudinal behavior caused by vehicles through comparative analysis and (2) to discuss influencing factors and propose control measures of girder longitudinal displacement during normal operation period.

\section{Engineering Background}

2.1. Bridge Description. The Aizhai bridge (Figure 1), a single-span steel suspension bridge, crossing the Dehang Grand Canyon with deep steep and complex geology along the highway between Jishou and Chadong in Hunan Province, carries the Changsha to Chongqing Expressway. As shown in Figure 1(b), the layout of the main cable is $242 m+1176 m+116 m$; meanwhile, the total length of the bridge is $1073.65 \mathrm{~m}$. The bridge also has the longest main span crossing Grand Canyon in the world when it was opened to traffic in 2012.

The two bridge towers, namely, the Jishou and Chadong towers, are made of reinforced concrete and constructed in situ. They are $130 \mathrm{~m}$ high with two crossbeams and $62 \mathrm{~m}$ high with one crossbeam, respectively. Thus, the suspension cable has a sag ratio of $1: 9.6$. The double main cables, which are paralleled to each other with the central distance of $27 \mathrm{~m}$, are supported by the four saddles installed at the top of the tower. Then, they are fixed to gravity anchorage and tunnel anchorage on the Jishou and Chadong sides, respectively. The steel truss girder with a total length of $1000.5 \mathrm{~m}$ is adopted for the bridge stiffening girder, which consists of main trusses, top and bottom bracings, and transverse trusses. The main trusses are of Warren type and have a height of $7.5 \mathrm{~m}$ and a width of $27 \mathrm{~m}$. The stiffening girder is made of Q345 steel with an elastic modulus of $210 \mathrm{GPa}$, axial allowable stress of $200 \mathrm{MPa}$, bending allowable stress of 210 $\mathrm{MPa}$, and shear allowable stress of $120 \mathrm{MPa}$. And the parameters for the main components of the bridge are shown in Table 1.

2.2. Displacement Monitoring System. The girder end displacement monitoring system was installed specifically on the Aizhai Bridge and began operation on February 25, 2016, to clearly understand the longitudinal behavior of the suspension bridge during normal operation period. Overall, a total of 10 sensors including four ultrasonic displacement sensors, four draw-wire displacement sensors, and two temperature sensors were installed to monitor the stiffening girder longitudinal movement and structural temperature. They were located at the truss-girder sections of the main girder ends. At each monitoring section, two ultrasonic displacement sensors were symmetrically located at two ends of the top chord, two draw-wire displacement sensors were symmetrically located at two ends of the bottom chord, and a temperature sensor was placed at middle of the bottom chord. The detailed location of the displacement and temperature sensors is shown in Figure 2, and the sampling frequency and the serial number of the sensors are listed in Table 2.

2.3. FE Model. A 3D FE model of the Aizhai Suspension Bridge is established by ANSYS, as shown in Figure 3. The tower, pier, and stiffening girder are simulated by space beam-column elements, and the main cables and suspenders are simulated as the link element (Link 10) that only bears tension. The gravity stiffness and large deformation nonlinear characteristics of the main cable are considered. In view of the rigid tower foundation, the tower bottom is modeled in the form of consolidation without regard to the pile-soil effect. The end of the stiffening girder is provided with lateral wind-resistant bearing, which would permit movement in the longitudinal direction and rotation about the transverse direction. The Rayleigh damping model is adopted in dynamic analysis, and the damping ratios that were associated with the first two longitudinal drift modes are 0.005 . The first seven vibration modes of the bridge are 


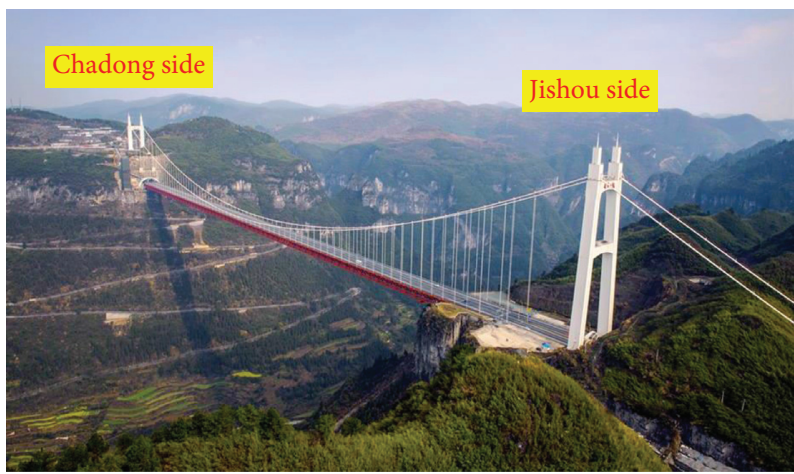

(a)

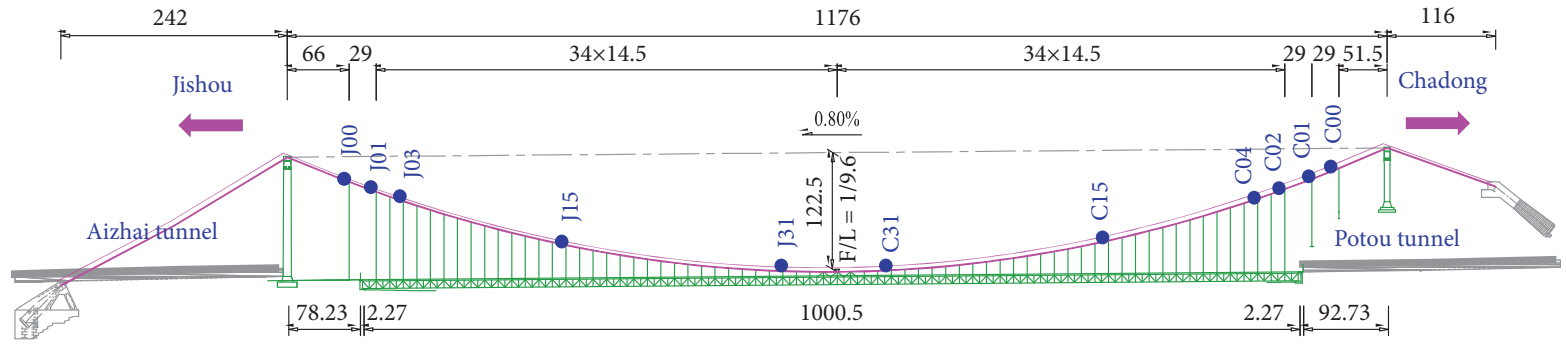

(b)

Figure 1: Aizhai Suspension Bridge (m): (a) realistic scene; (b) general layout.

TABle 1: Parameters for the main components of the bridge.

\begin{tabular}{|c|c|c|c|c|c|c|c|}
\hline Member & Detailed location & $A(\mathrm{~m} 2)$ & Iyy $(\mathrm{m} 4)$ & $I z z(\mathrm{~m} 4)$ & $\operatorname{Ixx}(\mathrm{m} 4)$ & $E(\mathrm{GPa})$ & $P\left(\mathrm{~kg} / \mathrm{m}^{3}\right)$ \\
\hline \multirow{7}{*}{ Stiffening girder truss } & Top chords & 0.06797 & 0.00458 & 0.00654 & 0.00804 & 210 & 8673 \\
\hline & Bottom chords & 0.05032 & 0.00326 & 0.00323 & 0.00482 & 210 & 8673 \\
\hline & Bottom chord end & 0.06000 & 0.00384 & 0.00381 & 0.00569 & 210 & 8673 \\
\hline & Web member & 0.02141 & 0.00134 & 0.00013 & $2.3983 \times 10^{-6}$ & 210 & 8673 \\
\hline & Web member end & 0.05472 & 0.00339 & 0.00225 & 0.00391 & 210 & 8673 \\
\hline & Diagonal webs & 0.02451 & 0.00184 & 0.00021 & $1.658 \times 10^{-6}$ & 210 & 8673 \\
\hline & Diagonal web end & 0.04560 & 0.00299 & 0.00156 & 0.00293 & 210 & 8673 \\
\hline \multirow{2}{*}{ Main cable } & Main span and Chadong bank & 0.46462 & - & - & - & 200 & 8043 \\
\hline & Jishou bank & 0.48112 & - & - & - & 200 & 8043 \\
\hline \multirow{3}{*}{ Suspenders } & $\mathrm{J} 00 / \mathrm{C} 01$ & 0.02386 & - & - & - & 115 & 8680 \\
\hline & $\mathrm{J} 01 / \mathrm{C} 00 / \mathrm{C} 02$ & 0.01591 & - & - & - & 115 & 8680 \\
\hline & $\mathrm{J} 02 \sim \mathrm{C} 03$ & 0.00779 & - & - & - & 115 & 8680 \\
\hline
\end{tabular}

$A$, sectional area; $I y y$, longitudinal bending moment inertia; $I z z$, transverse bending moment inertial; Ixx, torsional moment inertial; $E$, elastic modulus; $\rho$, density.

listed in Table 3, and the first two-order asymmetric vertical bending with longitudinal floating mode diagram that is closely related to the girder longitudinal displacement is shown in Figure 4.

\section{Field Monitoring Data Analysis}

Figure 5 displays displacement and temperature records from the six sensors installed in different positions at the truss-girder sections, which were obtained from March 1, 2016, to October 31, 2017. During this monitoring period, the measure displacement and temperature varied significantly with the seasonal alternation; moreover, the amplitude of displacement and temperature variation were
$418 \mathrm{~mm}$ and $37.2^{\circ} \mathrm{C}$, respectively, at Jishou side. Meanwhile, they were $452 \mathrm{~mm}$ and $40.1^{\circ} \mathrm{C}$ at Chadong side. In fact, several load factors contribute to girder end longitudinal displacement including temperature, traffic, or wind loading in the operational stage. Figure 3 can only superficially reflect the qualitative relationship between the temperature variation and the girder longitudinal movement.

In detail, daily monitoring data (e.g., August 15, 2017) were randomly selected to reveal daily longitudinal movement characteristic of the girder (Figure 6). Figure 6 plots a typical daily time-history curve of girder end longitudinal displacement for a suspension bridge, which is similar to a sinusoidal-shaped fluctuation curve with many small burrs and also been observed in other related studies [3,22,24]. 


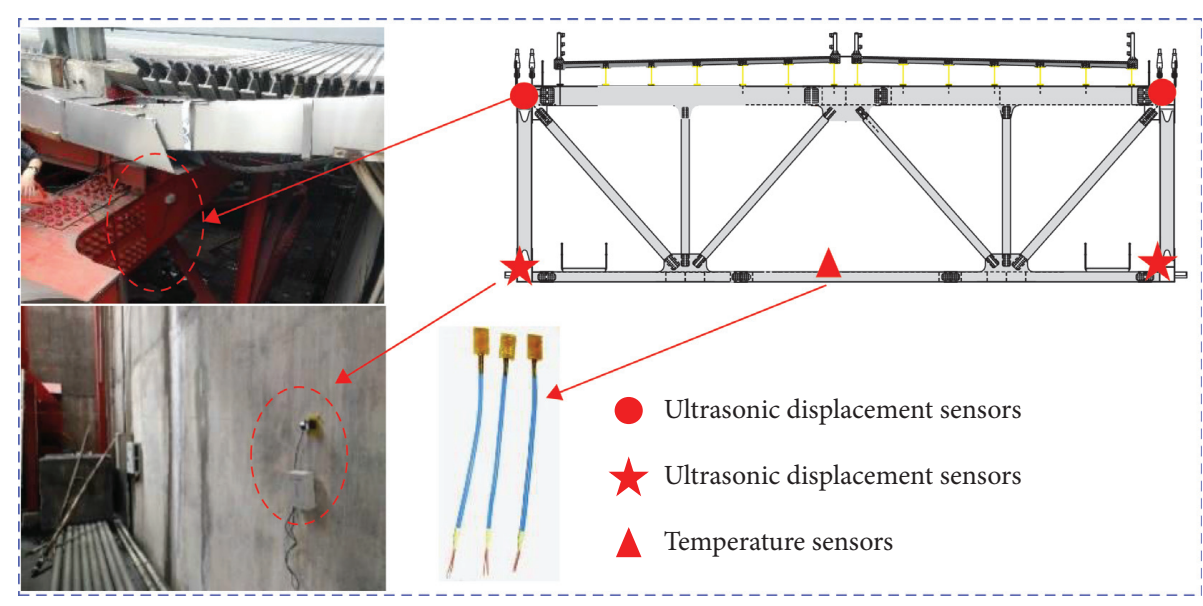

FIGURE 2: Monitoring sensors in the truss-girder section at the girder ends.

TABle 2: Instrumentations applied on Aizhai Bridge.

\begin{tabular}{|c|c|c|c|c|}
\hline Monitoring section & Serial number & Location details & Sampling frequency & Unit \\
\hline \multirow{5}{*}{ Jishou side } & ULDJ1 & Top chord (south) & 5 & $\mathrm{~mm}$ \\
\hline & ULDJ2 & Top chord (north) & 5 & $\mathrm{~mm}$ \\
\hline & DWDJ1 & Bottom chord (south) & 5 & $\mathrm{~mm}$ \\
\hline & DWDJ2 & Bottom chord (north) & 5 & $\mathrm{~mm}$ \\
\hline & TEMJ & Bottom chord (central) & 2 & ${ }^{\circ} \mathrm{C}$ \\
\hline \multirow{5}{*}{ Chadong side } & ULDC1 & Top chord (south) & 5 & $\mathrm{~mm}$ \\
\hline & ULDC2 & Top chord (north) & 5 & $\mathrm{~mm}$ \\
\hline & DWDC1 & Bottom chord (south) & 5 & $\mathrm{~mm}$ \\
\hline & DWDC2 & Bottom chord (north) & 5 & $\mathrm{~mm}$ \\
\hline & TEMC & Bottom chord (central) & 1 & ${ }^{\circ} \mathrm{C}$ \\
\hline
\end{tabular}

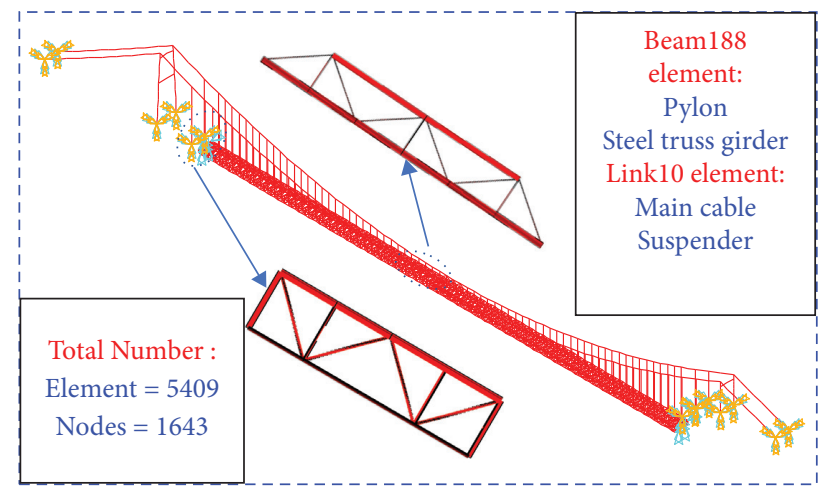

Figure 3: FE model of the Aizhai Bridge.

TABle 3: The vibration modes of the Aizhai Bridge.

\begin{tabular}{lccc}
\hline Mode no. & \multicolumn{2}{c}{ Frequency $(\mathrm{Hz})$} & Mode shape \\
\hline 1 & FEM res. & Field test res [29] & 1st symmetric lateral \\
2 & 0.0562 & 0.1005 & 1 st antisymmetric vertical + longitudinal floating \\
3 & 0.1158 & 0.1443 & 1 st antisymmetric lateral \\
4 & 0.1408 & 0.1759 & 1 st symmetric vertical \\
5 & 0.1595 & 0.2030 & 2 st symmetric vertical \\
6 & 0.2126 & 0.2822 & 2 st antisymmetric vertical + longitudinal floating \\
7 & 0.2540 & 0.3189 & 1 st symmetric torsional \\
\hline
\end{tabular}




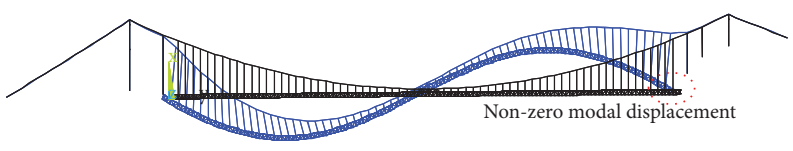

(a)

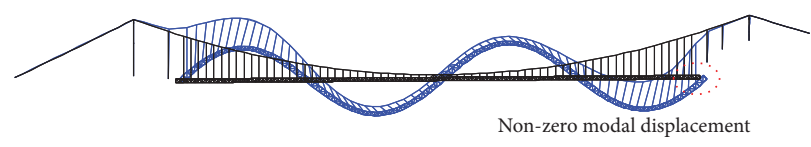

(b)

FIgURE 4: First two-order asymmetric vertical bending with longitudinal mode: (a) first order; (b) second order.

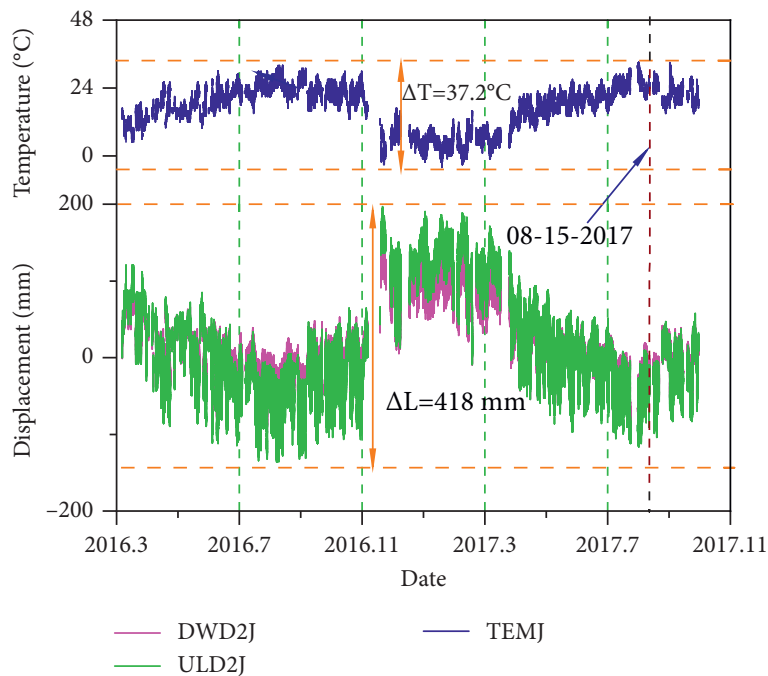

(a)

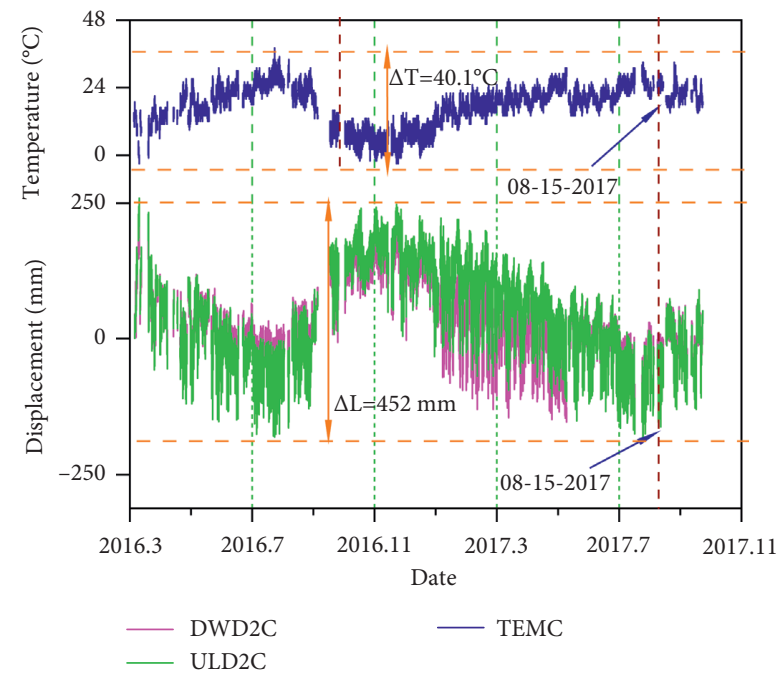

(b)

FIgURE 5: Displacement and temperature measured during monitoring period: (a) Jishou side; (b) Chadong side.

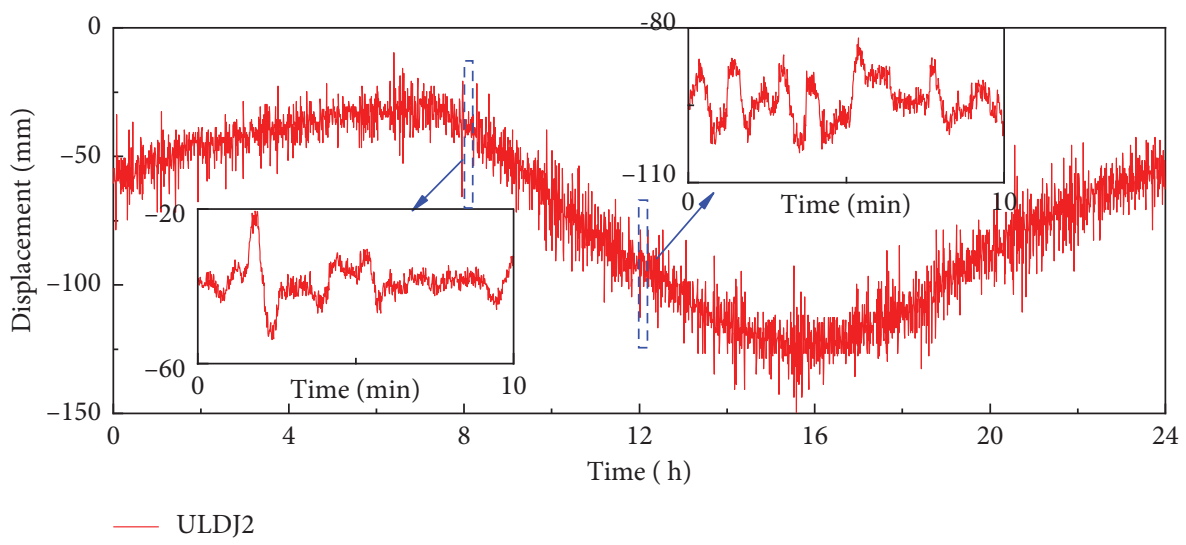

Figure 6: Time-history curve of daily longitudinal displacement at the girder end.

Meanwhile, these investigations all emphasized that the fluctuation trend of displacement time-history curve is caused by the slowly varying temperature, while the burr displacement is induced by the rapidly changing dynamic loads such as wind and vehicle load. This view can be confirmed in Figure 7, and the Fourier spectrum of the girder end longitudinal displacement of the bridge, which is obtained by the fast Fourier transform (FFT) from the daily time-history curve of the girder end longitudinal displacement, is shown in Figure 6.
Temperature-induced girder longitudinal displacement has been extensively researched. And this study focuses on the girder longitudinal movement caused by the vehicle load. Several $10 \mathrm{~min}$ displacement data were selected for vehicleinduced response analysis, where the temperature changes slightly and the wind speed is less than $2 \mathrm{~m} / \mathrm{s}$, so that the selected displacement responses are approximately assumed to be caused only by vehicles.

As observed from the partial view in Figure 6, the traffic loads may cause several centimeters of girder end 


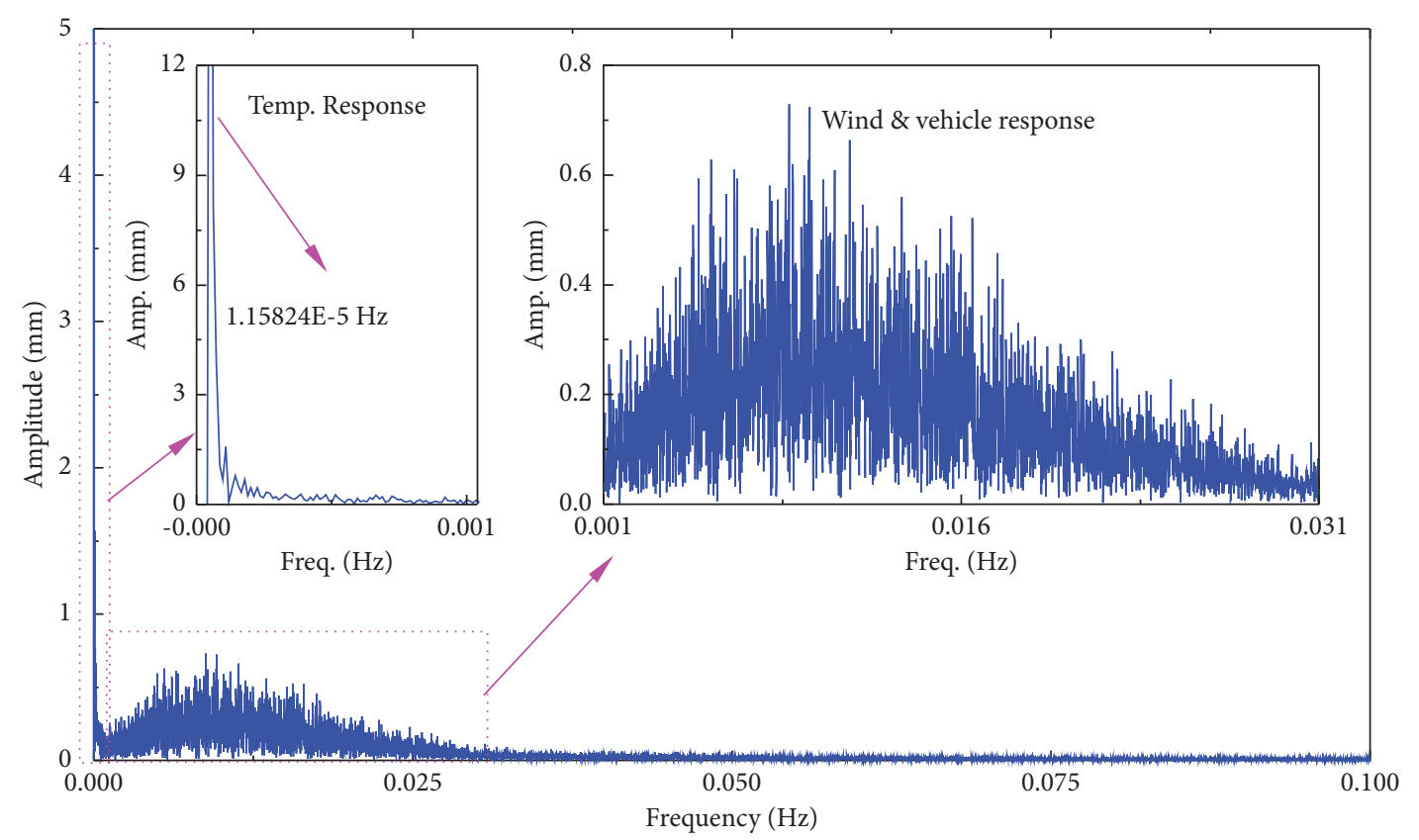

FIGURE 7: Fourier spectrum curve of daily longitudinal displacement at the girder end.

longitudinal displacement. Moreover, the Fourier spectrum curve of $10 \mathrm{~min}$ longitudinal displacement is plotted in Figure 8 by FFT. It indicates that the frequency band of girder end displacement response is mainly concentrated in $0-0.03 \mathrm{~Hz}$, which is far less than the frequency of first-order asymmetric vertical bending with longitudinal mode in Table $2(0.116 \mathrm{~Hz})$.

\section{Theoretical Analysis}

4.1. Static Longitudinal Behavior under Vertical Loads. To investigate the longitudinal girder movement mechanism of the suspension bridge under the moving vehicle load, the static deformation behavior of the structure under vehicle load (i.e., the vertical loads) should be researched before considering the dynamic displacement response under moving vehicle. Figure 9 shows a two-hinge singlespan suspension bridge considered in this study. There is no longitudinal support at either end of the girder, and the girder longitudinal movement is allowed to reduce the internal force effect under loads, especially seismic excitation.

The displacement, which reflects the total stiffness of the bridge system, is a macroscopic manifestation of structural deformation behavior characteristics. For suspension bridges, the structural behavior of the whole bridge depends on the mechanical properties of the main cables. When the vertical load is applied to the deck of suspension bridge, the main cables will undergo flexural deformation. Many scholars have conducted relevant research on this issue [30-33], but they all focused on the vertical flexural deformation instead of horizontal deflection.

In fact, when the displacement at the top of the tower and the elastic elongation of the cable are ignored, the cable geometric configuration will change due to the applied unbalanced loads (or the asymmetric loads). The deformation diagrams of suspension bridge under vertical asymmetric loads are presented in Figure 10. And the coupling relationship between vertical deflection and longitudinal displacement of the cable is analyzed on the basis of deflection theory as follows.

The $d$ s micro-element section of the main cable (Figure 11) is taken as the research object to analyze the deflection characteristic. The horizontal projection of change in cable length of a differential cable element $d w$ is given by the compatibility equation [34]:

$$
d w=\frac{H p}{E c A c \cos ^{3} \psi} d x+\frac{\alpha T}{\cos ^{2} \psi} d x-\frac{d y}{d x} d \eta,
$$

where $H \mathrm{p}=$ horizontal cable force component due to live load; $E c A c=$ cable axial stiffness; $T=$ temperature change in suspension cable; $\alpha=$ coefficient of thermal expansion; $\Psi=$ cable inclination angle; $\eta=$ cable deflection under live load; $y=$ cable ordinate under dead load; and $x=$ the horizontal coordinate along the axis of the deck.

Equation (1) indicates that $d w$ consists of three parts. The first two are the elastic elongation deformation displacement caused by vertical live loads and temperature, respectively. Meanwhile, the last is the longitudinal deformation displacement induced by the cable vertical deflection $\eta$, and this reveals the cable deformation characteristics that the vertical displacement is coupling with the longitudinal. Without regard to temperature and the elastic elongation induced by live loads [35], Equation (1) can be written more simply as

$$
d w=-\frac{d y}{d x} d \eta
$$

Then, the cable horizontal displacement $u(x)$ can be written as 


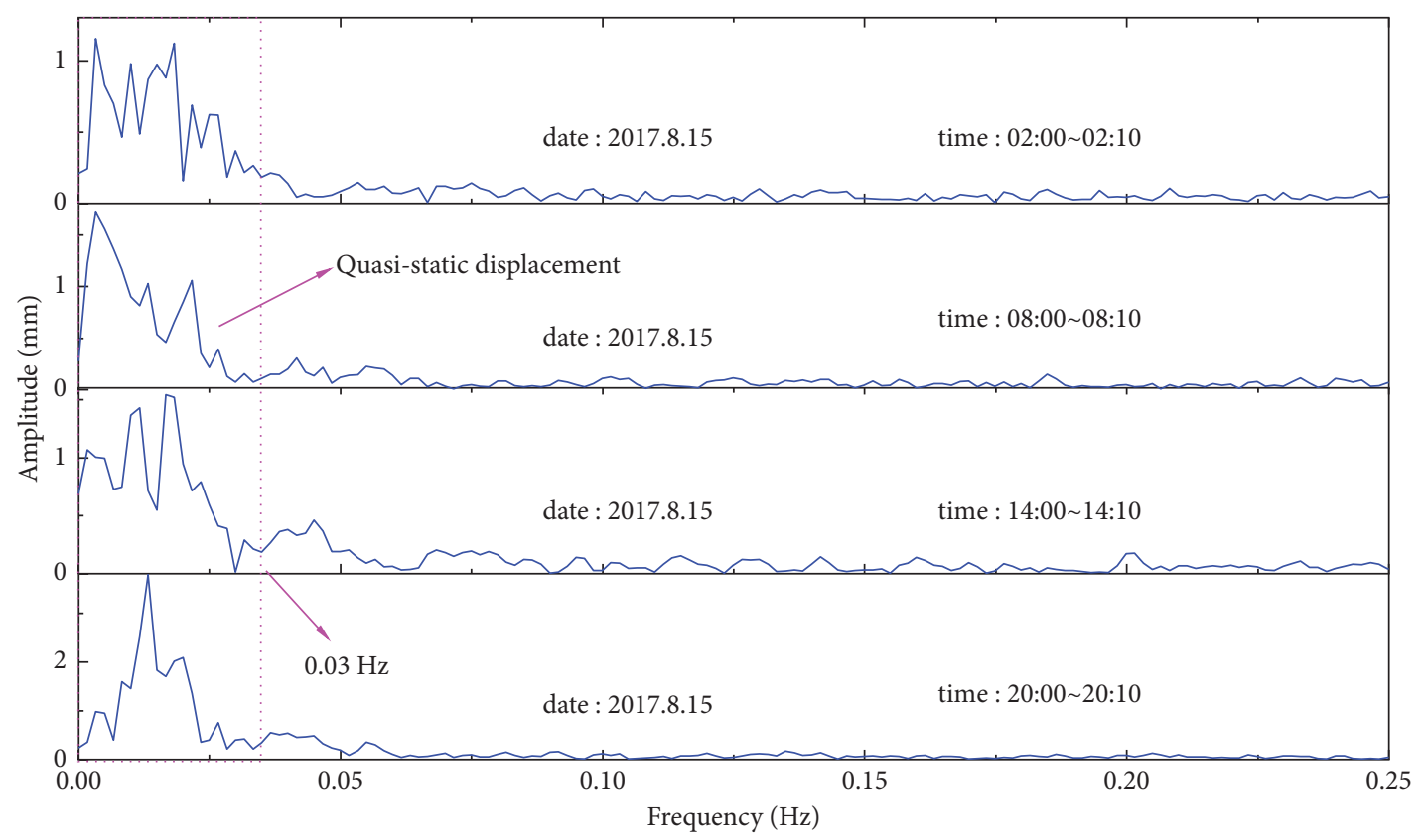

Figure 8: Fourier spectrum curve of 10 min longitudinal displacement at the girder end.

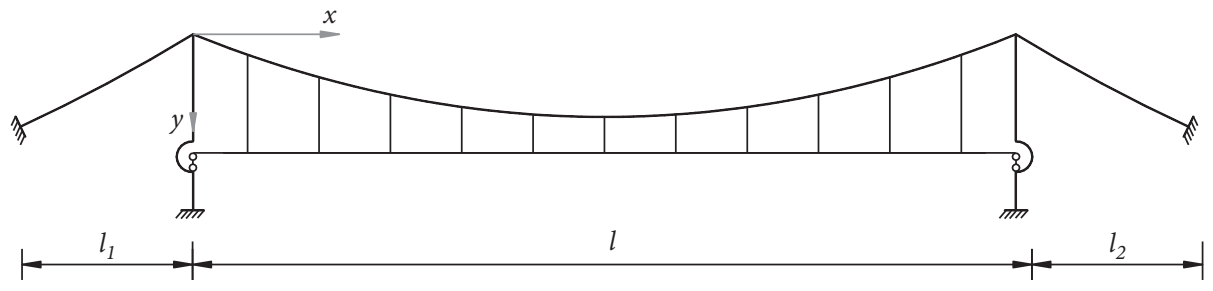

FIgURE 9: Geometry and coordinate system of a single-span suspension bridge.

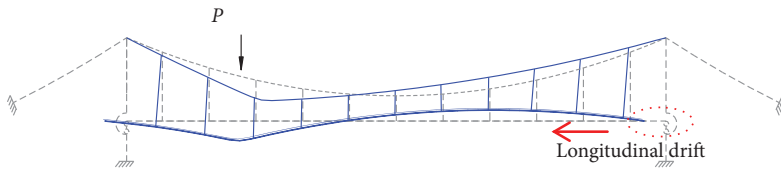

(a)

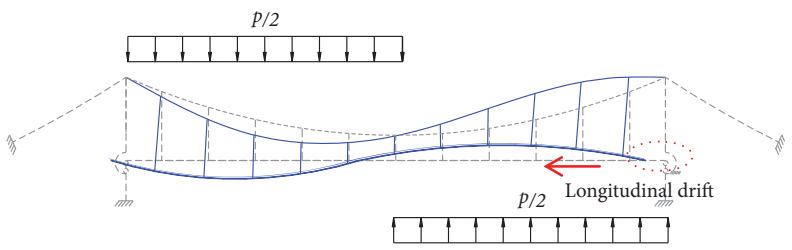

(b)

Figure 10: Deformation of a suspension bridge under asymmetric load: (a) a single vertical load case; (b) antisymmetric uniformly distributed load case.

$$
w(x)=-\int_{0}^{x} \frac{\mathrm{d} y}{\mathrm{~d} x} \mathrm{~d} \eta=-\int_{0}^{x} \frac{\mathrm{d} y}{\mathrm{~d} x} \frac{\mathrm{d} \eta}{\mathrm{d} x} \mathrm{~d} x
$$

Equations (2) or (3) shows that the vertical deflection of the cable induced by vertical live loads is accompanied by the longitudinal horizontal displacement. Notably, any form of loads can be decomposed into symmetrical and antisymmetric loads based on mechanical theory, and it is only the asymmetric vertical loads applied to the deck that may cause the girder longitudinal displacement. However, symmetrical vertical loads may cause symmetrical deformation of the suspension bridge, which fails to contribute to the girder longitudinal movement. When asymmetric vertical loads, especially the antisymmetric vertical loads, are applied to the deck of the suspension bridge, then the girder and cable undergoes approximately antisymmetric vertical deflection accompanied by longitudinal drift, which result in the static displacement response of the girder, as shown in Figure 10(b).

An exact analytic solution is difficult to obtain from Equation (2) due to the complex function expression of $\eta$. However, $u(x)$ can be solved in some ideal cases with 


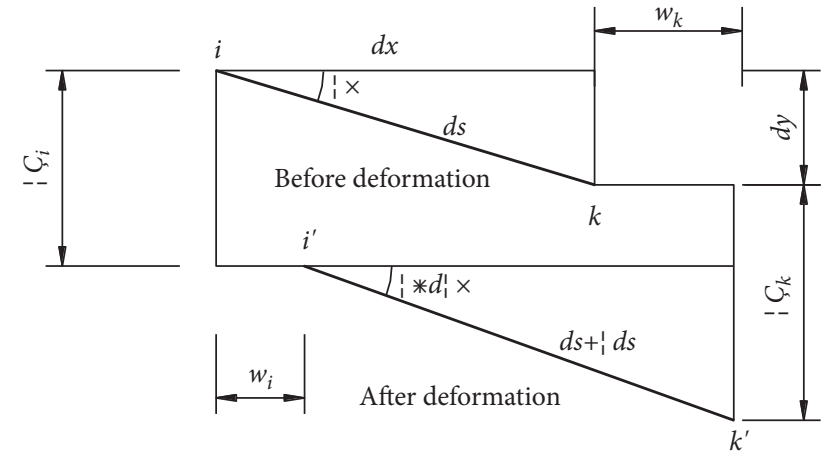

Figure 11: Deformation and displacement of the main cable microelement.

appropriate approximation assumptions, such as the load case shown in Figure 10(b).

The cable geometry under dead load is parabolic and can be written as

$$
y=\frac{4 f}{l^{2}} x(l-x)
$$

and the cable deflection under antisymmetric uniformly distributed load is a sine curve that can be expressed as

$$
\eta=A \sin \frac{2 \pi x}{l}
$$

where $A$ is the maximum of cable vertical deflection.

Substituting Equations (4) and (5) to Equation (3), Equation (3) will be rewritten as

$$
u(x)=-\frac{4 A f}{\pi L}\left[\left(1-\frac{2 x}{L}\right) \pi \sin \left(\frac{2 \pi x}{L}\right)-\cos \left(\frac{2 \pi x}{L}\right)+1\right] .
$$

The cable longitudinal displacement curve is drawn as shown in Figure 12. And the figure shows that the cable longitudinal displacement varies with its horizontal coordinates and presents an analogous double wave peak curve with its maximums occurring at approximately $l / 4$ and $3 l / 4$. This homodromous but unequal cable longitudinal displacement causes the suspenders to incline; as a result, the girder moves longitudinally as a whole. Notably, the cable longitudinal displacement determines that of the girder but not the same, and the correlation between them is affected by several factors, such as gravity stiffness, load cases, and the connection between the cables and girder. Consequently, the analytical solution of the girder longitudinal displacement induced by vertical loads is difficult to obtain and is generally solved by numerical methods.

4.2. Under Vertical Moving Loads. Without considering longitudinal vibration temporarily, the linear vibration equation of suspension bridge system under vertical load $p$ $(x, t)$ can be expressed as

$$
E I \frac{\mathrm{d}^{4} \eta}{\mathrm{d} x^{4}}-H_{0} \frac{\mathrm{d}^{2} \eta}{\mathrm{d} x^{2}}+C \dot{\eta}+m \ddot{\eta}=p(x, t)
$$

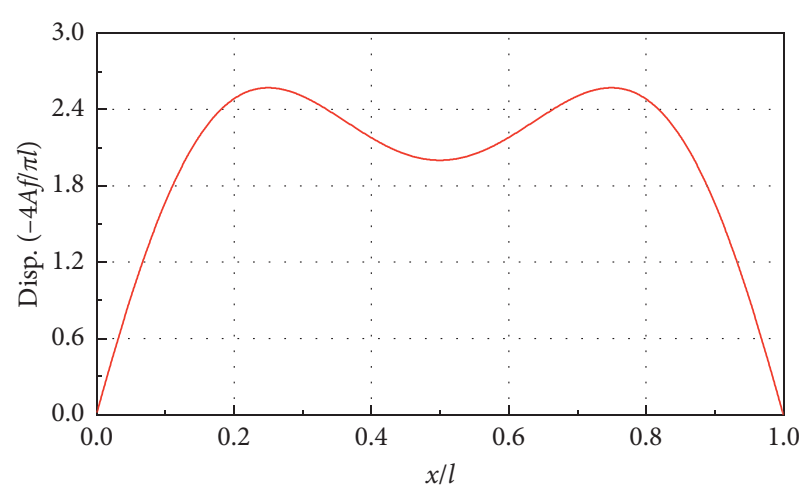

FIgURE 12: Longitudinal displacement of the main cable under antisymmetric uniformly distributed load.

where $E I$ is the flexural rigidity of stiffening girder, $H_{0}$ is the horizontal cable force component at the static equilibrium position, $C$ is the structural damping coefficient, and $m$ is the mass per unit deck length.

The dynamic deflection of the flexural vibration of the suspension bridge is assumed to be

$$
\eta(x, t)=\sum_{n=1}^{\infty} q_{n}(t) \cdot \varphi_{n}(x),
$$

where $q_{n}(t)$ denotes the $n$th modal coordinate and $\varphi_{n}(x)$ denotes the $n$-order vibration mode vector.

Substituting Equations (8) to (7) and using mode shape orthogonality, the $n$-order equation of motion without the effect of structural damping in modal coordinate system can be expressed as

$$
\ddot{q}_{n}(t)+\omega_{n}^{2} q_{n}(t)=Q(t),
$$

where $\omega_{n}^{2}=E I \int_{0}^{l} \varphi_{n}^{(4)} \varphi_{n} d x-H_{0} \int_{0}^{l} \varphi_{n}^{\prime \prime} \varphi_{n} \mathrm{~d} x / m \int_{0}^{l} \varphi_{n}^{2}(x) \mathrm{d} x$ is $n$-order natural vibration frequency of the suspension bridge, and the generalized load is

$$
Q(t)=\frac{\int_{0}^{l} p(x, t) \varphi_{n} \mathrm{~d} x}{m \int_{0}^{l} \varphi_{n}^{2}(x) \mathrm{d} x} .
$$

For long-span suspension bridges, the vehicle mass and the body length are far less than the bridge structural system mass and the bridge span, respectively. This study aims to reveal the mechanism of the displacement response of the girder and grasp its overall response characteristics under vehicle load without considering the vibration effect of the vehicle itself and the influence of coupling effects between the moving loads and bridge deformations temporarily. Thus, the moving vehicle is approximately simulated as moving constant load, and then, the generalized load can be expressed as

$$
Q(t)=\frac{\int_{0}^{l} p \delta(x-v t) \varphi_{n} \mathrm{~d} x}{m \int_{0}^{l} \varphi_{n}^{2}(x) \mathrm{d} x}=\frac{p \varphi_{n}(v t)}{m \int_{0}^{l} \varphi_{n}^{2}(x) \mathrm{d} x},
$$

where $p$ is the moving constant load and $\delta$, which is the Dirac delta function, is defined as 


$$
\delta(x-v t)= \begin{cases}0, & x \neq v t \\ 1, & x=v t .\end{cases}
$$

Substituting Equations (11) to (9), Equation (9) can be rewritten as

$$
\ddot{q}_{n}(t)+\omega_{n}^{2} q_{n}(t)=\frac{p \varphi_{n}(v t)}{m \int_{0}^{l} \varphi_{n}^{2}(x) \mathrm{d} x} .
$$

Note that only longitudinal drift modes are concerned for the girder longitudinal displacement or longitudinal vibration under moving load, and these modes are always accompanied by the asymmetric vertical flexural modes for suspension bridge, as shown in Figure 4. Moreover, the antisymmetric vertical bending mode function of the girder is assumed as

$$
\varphi_{n}=\sin \left(\frac{2 \pi n x}{l}\right)
$$

Substituting Equations (14) to (13), the solution of the equation can be obtained as

$$
\left.q(t)=\frac{2 P}{m l} \sum_{n=1}^{N} \frac{1}{\omega_{n}^{2}-\Omega_{n}^{2}}\left(\sin \Omega_{n} t-\frac{\Omega_{n}}{\omega_{n}} \sin \omega_{n} t\right)\right),
$$

where the generalized disturbance frequency $\Omega_{n}=2 \pi n v / l$.

As shown in Figure 4, the antisymmetric vertical bending modes are always coupled with longitudinal drift, and longitudinal nonzero displacement (i.e., modal coordinates) of the girders is assumed to be equal to $\varphi_{x n}$. Then, the corresponding girder longitudinal displacement $u_{\mathrm{b}}(t)$ can expressed as

$$
u_{b}(t)=\frac{2 P}{m l} \sum_{n=1}^{N} \frac{1}{\omega_{n}^{2}-\Omega_{n}^{2}}\left(\sin \Omega_{n} t-\frac{\Omega_{n}}{\omega_{n}} \sin \omega_{n} t\right) \varphi_{x n} .
$$

Therefore, the longitudinal vibration of suspension bridge under moving loads is presented as simple harmonic forced vibration at generalized disturbance frequency $2 \pi n v /$ $l$ in the modal coordinate system.

If the moving speed is very small, then $\Omega_{n}$ is far less than the natural frequency of the structure $\omega_{n}$ and the structure response is quasi-static under moving load. If only the first mode is considered, then the longitudinal displacement of the girder can be expressed as

$$
u_{b}(t)=u_{b 0}(t) \sin \frac{2 \pi}{l} x
$$

where $u_{b 0}$ is the static longitudinal displacement amplitude of the girder and $l$ is the displacement wavelength of sinusoidal curve, and it is also equal to the span of the main girder of a single-span suspension bridge.

When the generalized longitudinal disturbance frequency, $f_{p}=v / l$, is equal to the bending-longitudinal coupling vibration frequency $f_{n}$ of some order of the system, the longitudinal resonance phenomenon will occur, and the resonance speed required is $v_{\mathrm{br}}=l f_{n}$.

\section{Numerical Study}

5.1. Quasi-Static Response. The quasi-static response of the suspension bridge under a single slowly moving load with a magnitude of $550 \mathrm{kN}$, the standard value of vehicle weight in bridge design code in China, is first investigated on the basis of the FE model of the Aizhai Bridge. The longitudinal displacement response of the girder end under that load case is obtained, as shown in Figure 13. As observed, the shapes of the curves on the figure are similar to the sinusoids and the influence line of longitudinal displacement at the girder end of suspension bridge [2]. When the load is applied to the middle of the span, the displacement of the girder end is approximately equal to zero, while in the $1 / 4$ of the span, it approximately reaches the maximum.

As shown in Figure 13(a), the longitudinal displacement curves at different positions of the girder ends are similar but not the same, and the slight differences of the curves are caused by the vertical bending (elastic deformation) of the girder. If that longitudinal displacement induced by flexural deflection is ignored, then the longitudinal displacement of the girder (i.e., rigid body longitudinal displacement) can be calculated by averaging the four curves in Figure 13(a). In this way, the girder displacement curve is closer to the sinusoid (the idealized displacement curve in Figure 13(b), which is adopted by Equation (17)).

5.2. Dynamic Response. The simulation analysis of a single moving load at different speeds traveling across the bridge is conducted to investigate the influence of the speed effect of moving load on the girder longitudinal of the suspension bridge. Meanwhile, the dynamic amplification factor $(D A F)$ is introduced to assess the dynamic effect caused by moving loads, and it is defined as

$$
D A F=\frac{R_{D \max }}{R_{S \max }}
$$

where $R_{D \max }$ and $R_{S \max }$ are the absolute maximum dynamic and static responses, respectively, including displacement, stress, and internal force of the bridge, and the response in this study is the girder longitudinal displacement.

Figure 14 illustrates the longitudinal displacement response of the girder under a single moving load at different speeds $(0-140 \mathrm{~m} / \mathrm{s})$. The DAFs for the longitudinal displacement at the girder end of the suspension bridge are shown in Figure 15. Figures 14 and 15 indicate that the longitudinal displacement response is extremely sensitive to the speed of the moving load, and the dynamic displacement response is magnified with the increasing speed. In particular, when the speed reaches about the resonance speed, $v_{\mathrm{br}}=l f_{1}=1000.5 \times 0.116=116 \mathrm{~m} / \mathrm{s}$, the vertical coupling longitudinal resonance occurs; the displacement response reaches the maximum and subsequently decreases gradually (Figure 15).

5.3. Analysis of Influencing Factors. Several factors, including structural damping ratio, dampers installed at the girder ends, and bearing friction resistance, are investigated to analyze their effect on vehicle-induced 


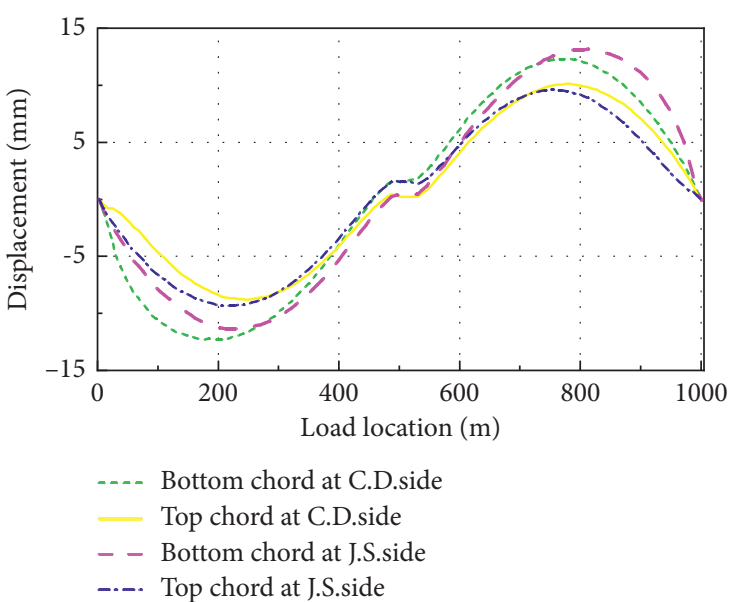

(a)

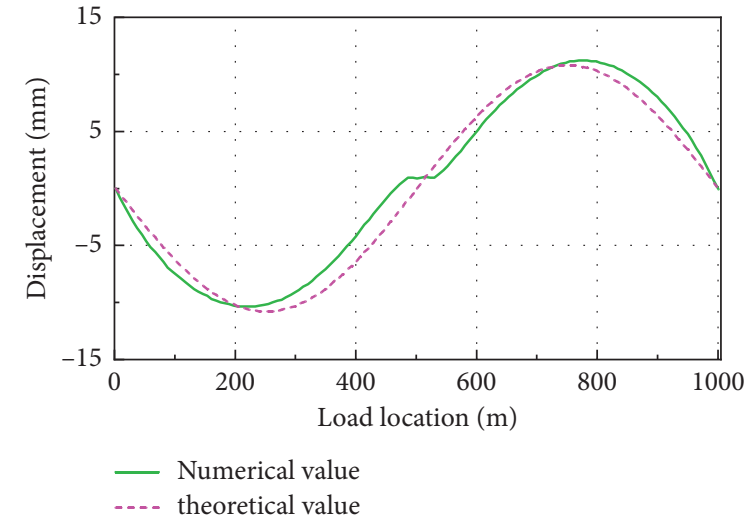

(b)

Figure 13: Longitudinal displacement at the end of the girder induced by a load at a slow speed moving on the bridge: (a) longitudinal displacement at different positions of girder ends; (b) average longitudinal displacement and equivalent longitudinal displacement at the ends.

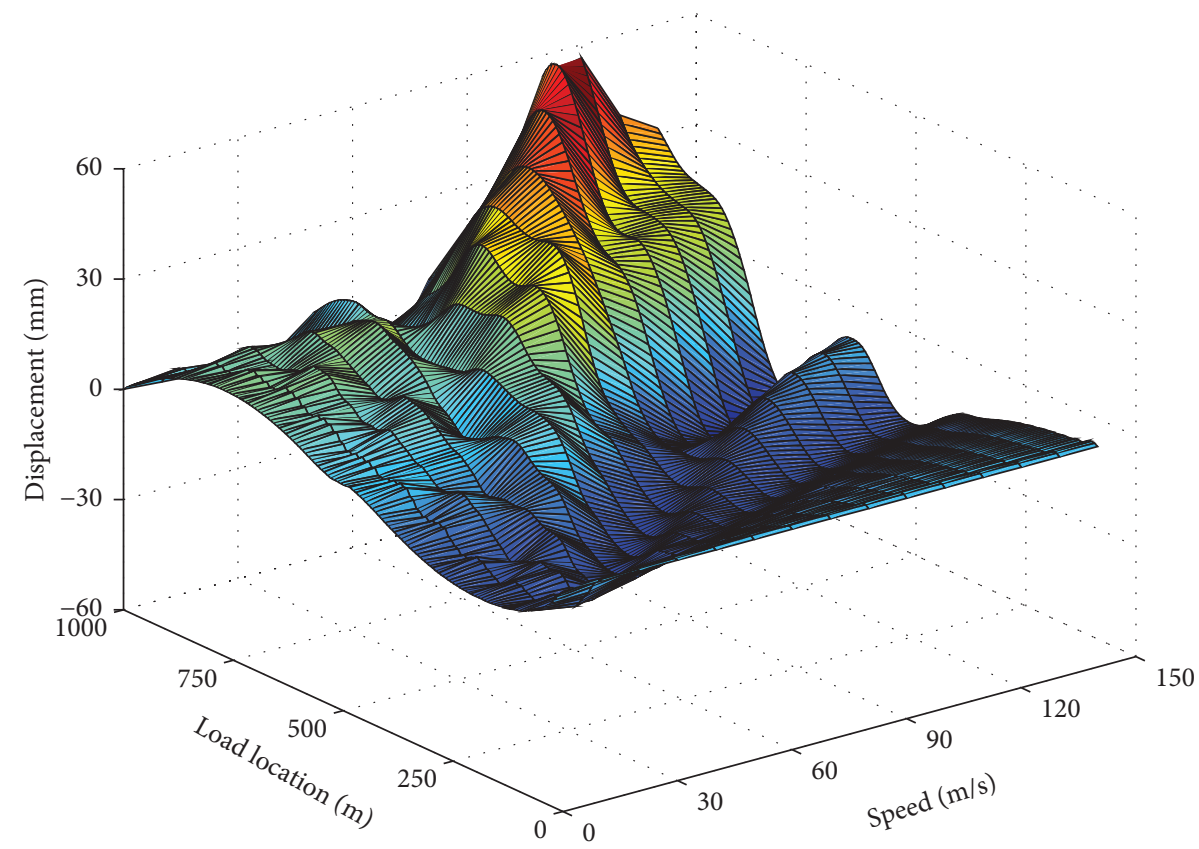

Figure 14: Longitudinal displacement at the end of the girder of the suspension bridge under a single moving load.

longitudinal vibration under different moving load cases and to further explore the response characteristics of vehicle-induced girder longitudinal displacement response. Table 4 lists the various combinations of factors considered, while Table 5 displays different moving load cases, including single moving load, moving load series, and uniform load flow.

Figures 16 and 17 present the longitudinal displacement response caused by the three different moving load cases in consideration of different influencing factors in Table 4. The plots in the figures indicate that the displacement response of girder end consists of quasi-static and dynamic effects under moving loads. However, the dynamic effect rather than the quasi-static effect can be reduced to some certain extent as a result of the damper installed on the girder ends or the structure damping and the bearing friction resistance. In particular, only the quasi-static effect displacement is left, while the dynamic effect is completely suppressed due to the synergistic effect of damper and bearing friction (the curves of $\xi=0.005+$ damper + friction in Figure 16).

The single moving load case is taken as an example for further illustration, as shown in Figure 16(b). The figure indicates that the first-order dominant frequency of displacement response is approximately equal to the generalized longitudinal disturbance frequency of moving load across the bridge, $f_{\mathrm{p}}=30 / 1000.5=0.030 \mathrm{~Hz}$. Meanwhile, the 


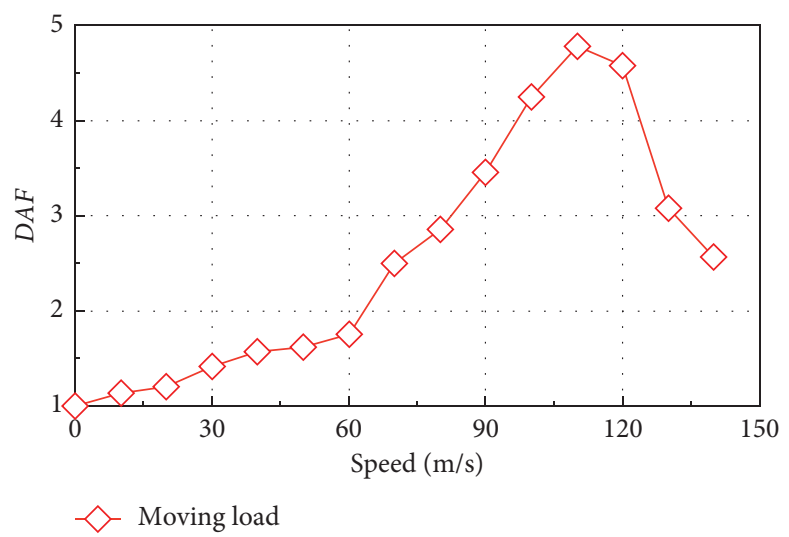

Figure 15: DAFs for longitudinal displacement at the end of the girder under a single moving load.

TABLE 4: Cases for calculation of different damping conditions.

\begin{tabular}{lccc}
\hline Factor no. & Damping ratio & Damper parameters & Friction \\
\hline 1 & 0.005 & Ignored & Ignored \\
2 & 0.005 & $C=5000 \mathrm{kN} /(\mathrm{m} / \mathrm{s})^{\alpha}, \alpha=0.4$ & Ignored \\
3 & 0.005 & $C=5000 \mathrm{kN} /(\mathrm{m} / \mathrm{s})^{\alpha}, \alpha=0.4$ & Counted \\
4 & 0.03 & Ignored & Ignored \\
\hline
\end{tabular}

TABle 5: Cases of different moving loads.

\begin{tabular}{lcccc}
\hline Load cases & Load value $(\mathrm{kN})$ & Load number & Load space $(\mathrm{m})$ & Speed $(\mathrm{m} / \mathrm{s})$ \\
\hline Single moving load & 550 & 1 & - & 30 \\
Moving load series & 550 & 10 & 100 & 25 \\
Uniform load flow & 550 & - & 100 & 25 \\
\hline
\end{tabular}

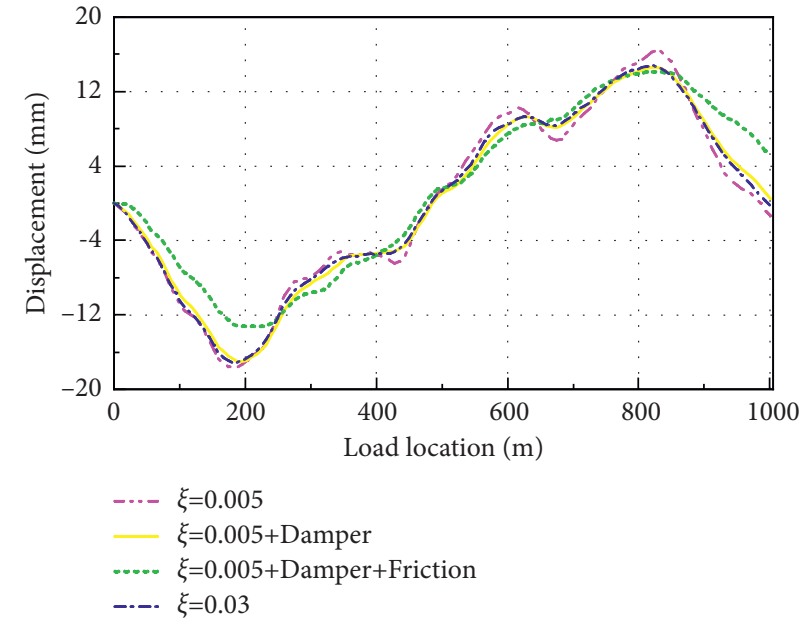

(a)

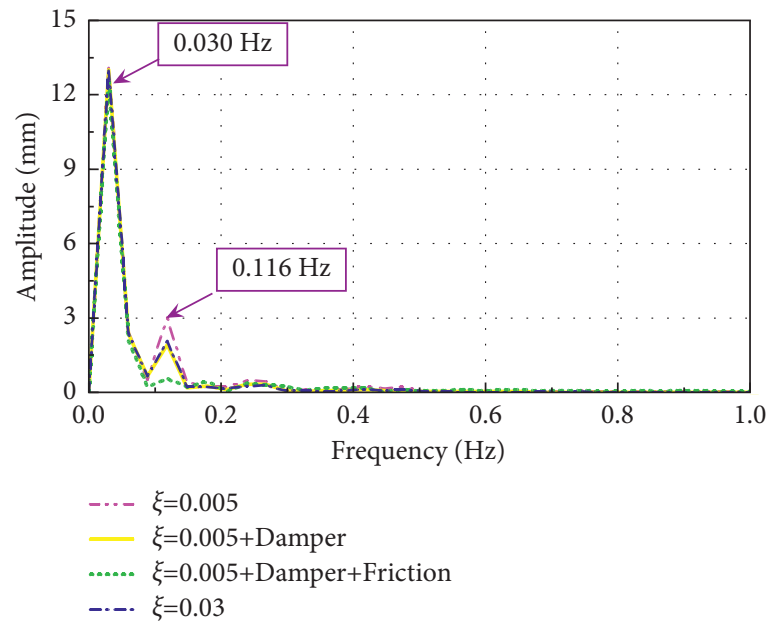

(b)

FIGURE 16: Girder end longitudinal displacement of the suspension bridge under a single moving load at $30 \mathrm{~m} / \mathrm{s}$ : (a) time history of longitudinal displacement; (b) Fourier spectrum of longitudinal displacement.

second-order dominant frequency of displacement response is approximately equal to the first-order asymmetric vertical bending coupling longitudinal drift modal frequency $(0.116 \mathrm{~Hz})$. The structural damping and installed longitudinal damper have a little restraining effect on the dynamic displacement. However, no first-order asymmetric vertical bending vibration mode is observed under the combined effect of damper and bearing friction. Therefore, 


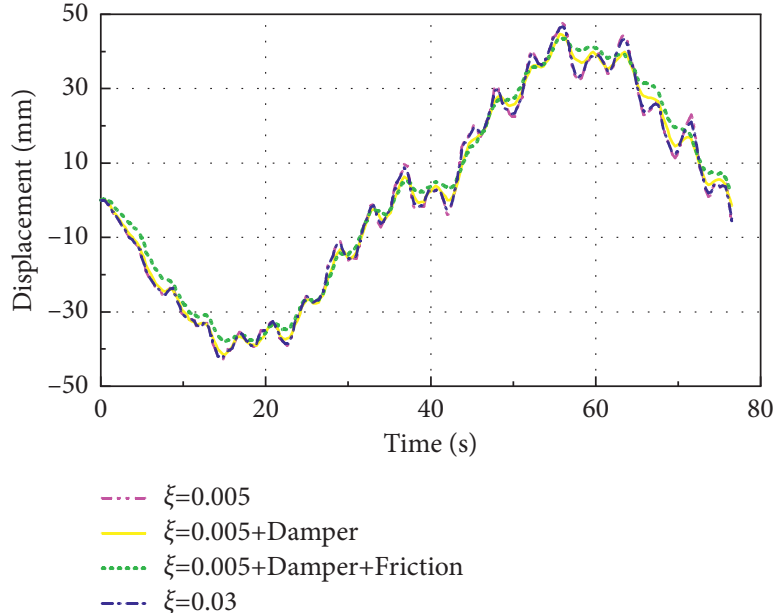

(a)

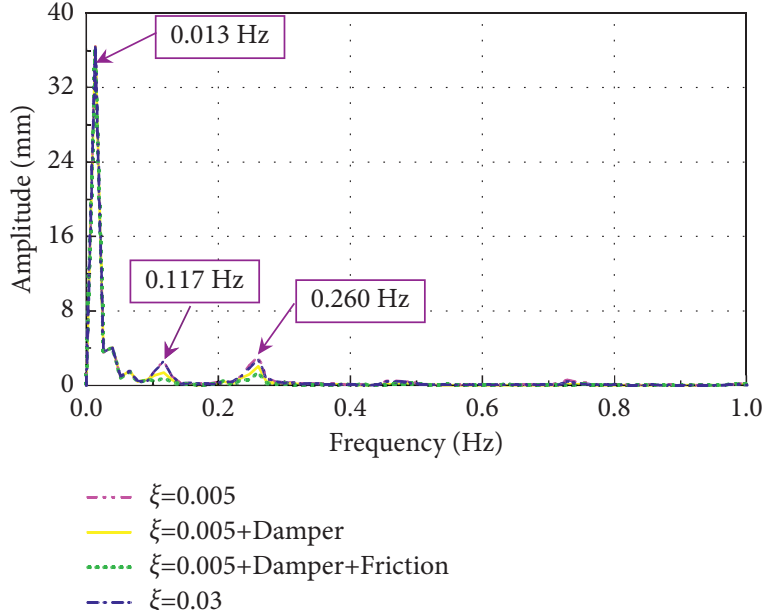

(b)

Figure 17: Girder end longitudinal displacement of the suspension bridge under a series of moving loads at $25 \mathrm{~m} / \mathrm{s}$ : (a) time history of longitudinal displacement; (b) Fourier spectrum of longitudinal displacement.

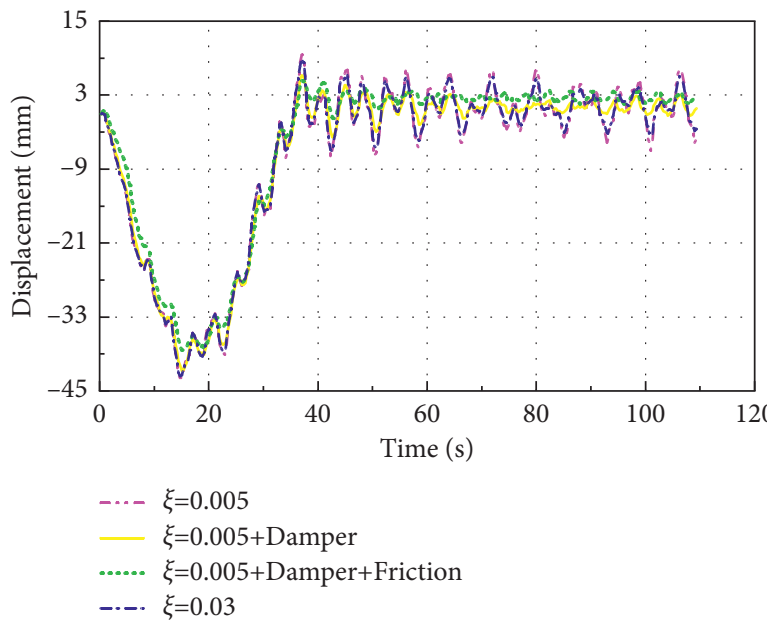

(a)

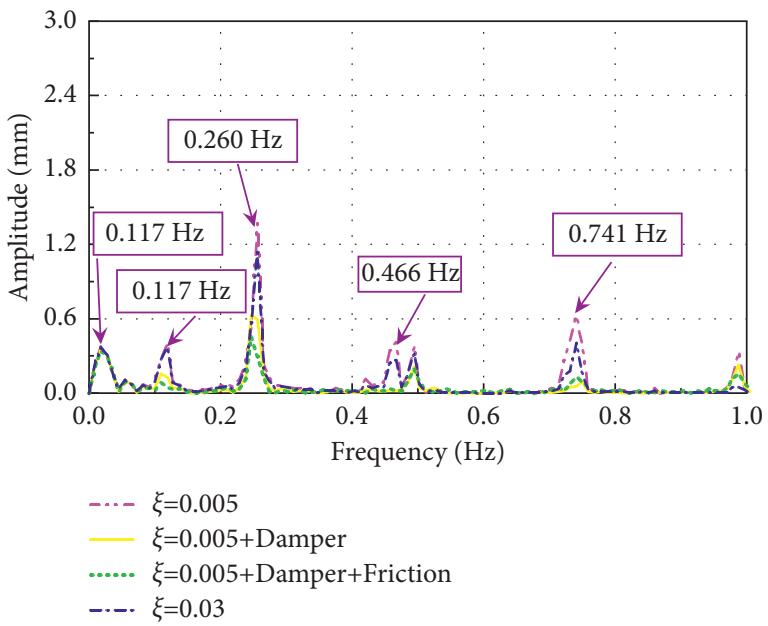

(b)

Figure 18: Girder end longitudinal displacement of the suspension bridge under a series of moving loads at $25 \mathrm{~m} / \mathrm{s}$ : (a) time history of longitudinal displacement; (b) Fourier spectrum of longitudinal displacement.

the influence of friction resistance on dynamic displacement cannot be ignored.

For the normal speed of the driving vehicles on highway bridge (no more than $40 \mathrm{~m} / \mathrm{s}$ in general), the corresponding generalized excitation frequency of moving load is often far less than the natural frequency of the structure. That is, the forced vibration is far from the firstorder longitudinal drift resonance region of the bridge, as shown in Figure 16(b).

The displacement response characteristic under moving load series is similar to that under single moving load. However, that is not the same for the uniform load flow case (Figure 18). The dynamic response is magnified due to that the idealized traffic flow forms periodic excitation on the bridge, while quasi-static effect is largely counterbalanced by uniformly distributed loads on the deck. In fact, uniform load flow case is rare in engineering.

\section{Conclusions}

On the basis of the background of Aizhai Bridge, this study analyzes the response characteristics and influencing factors of girder longitudinal displacement of the suspension bridge under moving vehicle load.

(1) The analysis results both in time domain and frequency domain based on field measured data indicate that the girder of the Aizhai Bridge moves quasi-statically and reciprocates longitudinally with centimeter amplitude under normal operational loads, which is verified by finite element numerical simulation.

(2) The coupling relationship between the vertical and longitudinal displacements of the main cable is deduced based on the cable geometric deformation 
theory. The imposed vertical load will contribute to the configuration change of the cable, that is, the deformation with vertical deflection and longitudinal drift, which leads to the girder longitudinal displacement and movement.

(3) The vehicle is modeled as a moving concentrated load, and the numerical simulation analysis for vehicle-induced vibration is carried out. Then, the longitudinal displacement response characteristic of the girder is obtained, which reveals the mechanical mechanism of the girder longitudinal movement of suspension bridge caused by moving load. However, the numerical results cannot be directly applied to practical projects given that the vehicle-bridge coupling and random vehicle flow effects are ignored. In view of this, more reliable girder longitudinal displacement will be further investigated in the future.

(4) The moving load induces the longitudinal vibration of the floating girder of suspension bridge. When the speed of the moving load is small, the longitudinal behavior of the girder is quasi-static; however, the dynamic response of that is magnified with the increase of moving speed in a certain range of moving speed. There is a theoretically possible resonance speed, $v_{\mathrm{br}}=l f_{1}$, which is generally far greater than the speed of the driving vehicles on the highway bridge.

(5) Under moving vehicle with normal speed, the forced quasi-static longitudinal movement of the girder is accompanied by the dynamic effects, which may induce excessive cumulative girder displacement. However, the dynamic effects can be eliminated to a great extent, as a result of the combined influence of damping, installed longitudinal damper, and bearing friction.

\section{Data Availability}

The data used to support the findings of this study are available from the corresponding author upon request.

\section{Conflicts of Interest}

The authors declare no conflicts of interest.

\section{Acknowledgments}

This study was sponsored by the Hunan Provincial Natural Science Foundation of China (Grant No. 2021JJ50143) and Hunan Science and Technology Talent Promotion Project in China (Grant No. 2019TJ-Y08), which are greatly acknowledged.

\section{References}

[1] Y. L. Xu and Y. Xia, Structural Health Monitoring of LongSpan Suspension Bridges, CRC Press, Boca Raton, FL, USA, 2011.
[2] G. Li, W. Han, X. Chen, and T. Guo, "Wear evaluation on slide bearings in expansion joints based on cumulative displacement for long-span suspension bridge under monitored traffic flow," Journal of Performance of Constructed Facilities, vol. 34, no. 1, Article ID 04019106, 2020.

[3] T. Guo, J. Liu, and L. Huang, "Investigation and control of excessive cumulative girder movements of long-span steel suspension bridges," Engineering Structures, vol. 125, pp. 217-226, 2016.

[4] T. Guo, L. Huang, J. Liu, and Y. Zhou, "Damage mechanism of control springs in modular expansion joints of long-span bridges," Journal of Bridge Engineering, vol. 23, no. 7, Article ID 04018038, 2018.

[5] Z. Sun and Y. Zhang, "Failure mechanism of expansion joints in a suspension bridge[J]," Journal of Bridge Engineering, vol. 21, no. 10, Article ID 05016005, 2016.

[6] Z. Sun, S. Ning, and Y. Shen, "Failure investigation and replacement implementation of short suspenders in a suspension bridge," Journal of Bridge Engineering, vol. 22, no. 8, Article ID 05017007, 2017.

[7] Z. Liu, T. Guo, L. Huang, and Z. Pen, "Fatigue life evaluation on short suspenders of long-span suspension bridge with central clamps," Journal of Bridge Engineering, vol. 22, no. 10, Article ID 04017074, 2017.

[8] Z. Liu, T. Guo, M. H. Hebdon, and W. Han, "Measurement and comparative study on movements of suspenders in longspan suspension bridges," Journal of Bridge Engineering, vol. 24, no. 5, Article ID 04019026, 2019.

[9] X. Liu, W. Han, Y. Yuan, X. Chen, and Q. Xie, "Corrosion fatigue assessment and reliability analysis of short suspender of suspension bridge depending on refined traffic and wind load condition," Engineering Structures, vol. 234, Article ID 111950, 2021.

[10] Z. Sun, Z. Zou, and Y. Zhang, "Utilization of structural health monitoring in long-span bridges: case studies," Structural Control and Health Monitoring, vol. 24, no. 10, p. e1979, 2017.

[11] Y. Li, M. Wu, Y. Zang, and S. Qing, "Effects of vertical rotation angle at girder ends on train running performance for largespan suspension bridges," China Civil Engineering Journal, no. 8, pp. 122-128, 2012.

[12] D. Wang, Y. Deng, and Y. Liu, "Influence of central buckle on suspension bridge dynamic characteristics and driving comfort," Journal of Central South University, vol. 22, no. 8, p. 3115, 2015.

[13] S. Arzoumanidis, A. Shama, and F. Ostadan, "Performancebased seismic analysis and design of suspension bridges," Earthquake Engineering \& Structural Dynamics, vol. 34, no. 45, pp. 349-367, 2010.

[14] M.-G. Yang and C. S. Cai, "Longitudinal vibration control for a suspension bridge subjected to vehicle braking forces and earthquake excitations based on magnetorheological dampers," Journal of Vibration and Control, vol. 22, no. 17, pp. 3659-3678, 2016.

[15] L. Liang, Z. Feng, and Z. Chen, "Seismic control of SDOF systems with nonlinear eddy current dampers[J]," Applied Sciences, vol. 9, no. 16, p. 3427, 2019.

[16] M. Zribi, N. B. Almutairi, and M. Abdel-Rohman, "Control of vibrations due to moving loads on suspension bridges," Nonlinear Analysis Modelling and Control, vol. 11, no. 11, pp. 293-318, 2006.

[17] B. S. Xing and X. F. Wang, "The singular function method based on the moving load deformation of suspension bridge," Advanced Materials Research, vol. 403-408, pp. 3059-3062, 2012. 
[18] S. H. Ju, H. T. Lin, C. C. Hsueh, and S. L. Wang, "A simple finite element model for vibration analyses induced by moving vehicles," International Journal for Numerical Methods in Engineering, vol. 68, no. 12, pp. 1232-1256, 2006.

[19] N. B. Almutairi, M. F. Hassan, M. Abdel-Rohman, and M. J. Terro, "Control of suspension bridge nonlinear vibrations due to moving loads," Journal of Engineering Mechanics, vol. 132, no. 6, pp. 659-670, 2006.

[20] M. G. Yang and Z. Q. Yang, "Longitudinal vibration control of floating system bridge subject to vehicle braking force with viscous dampers," Advanced Materials Research, vol. 446-449, pp. 1256-1260, 2012.

[21] A. Q. Li, Y. Ding, H. Wang, and T. Guo, "Analysis and assessment of bridge health monitoring mass data_- progress in research/development of "Structural Health Monitoring," Science China, vol. 55, no. 8, pp. 134-146, 2012.

[22] T. Guo, J. Liu, Y. Zhang, and S. Pen, "Displacement monitoring and analysis of expansion joints of long-span steel bridges with viscous dampers," Journal of Bridge Engineering, vol. 20, no. 9, Article ID 04014099, 2015.

[23] Z. Sun and H. Sun, "Jiangyin bridge: an example of integrating structural health monitoring with bridge maintenance," Structural Engineering International, vol. 28, no. 3, pp. 353356, 2018.

[24] J. Hu, L. Wang, X. Song, Z. Sun, J. Cui, and G. Huang, "Field monitoring and response characteristics of longitudinal movements of expansion joints in long-span suspension bridges," Measurement, vol. 162, Article ID 107933, 2020.

[25] Y. Zhang, H. Wang, Y. Baib, X. J. Maoa, X. Y. Changa, and L. B. Wang, "Switching Bayesian dynamic linear model for condition assessment of bridge expansion joints using structural health monitoring data," Mechanical Systems and Signal Processing, vol. 160, Article ID 107879, 2021.

[26] Y. Zhao, P. Huang, G. Long, Y. Yuan, and Y. Sun, "Influence of fluid viscous damper on the dynamic response of suspension bridge under random traffic load," Advances in Civil Engineering, vol. 2020, Article ID 1857378, 19 pages, 2020.

[27] F. Petrini, P. Olmati, and F. Bontempi, "Coupling effects between wind and train transit induced fatigue damage in suspension bridge," Structural Engineering \& Mechanics, vol. 70, pp. 311-324, 2019.

[28] W. Gao, G. Li, Q. Su, and W. Han, "Impact of rigid central clamps on longitudinal deformation of long-span suspension bridges under vehicle excitations," Structure and Infrastructure Engineering, pp. 1-15, 2021.

[29] D. Yan, H. Xu, Q. Pan, and K. Zhang, Technical Report: Field Load Test of Aizhai Bridge, Changsha University of Science and Technology, Changsha, China, 2012, In Chinese.

[30] L. T. Stavridis, "A simplified analysis of the behavior of suspension bridges under live load," Structural Engineering \& Mechanics, vol. 30, no. 5, pp. 559-576, 2008.

[31] R. A. Dorton, "Cable supported bridges: concept and design," Canadian Journal of Civil Engineering, vol. 13, no. 6, p. 401, 2012.

[32] J. M. W. Brownjohn, K.-Y. Koo, and A. Scullion, "Operational deformations in long-span bridges," Structure and Infrastructure Engineering, vol. 11, no. 4, pp. 556-574, 2015.

[33] D. Arco and C. Aparicio, "Preliminary static analysis of suspension bridges," Engineering Structures, vol. 23, no. 9, pp. 1096-1103, 2001

[34] G. P. Wollmann, "Preliminary analysis of suspension bridge," Journal of Bridge Engineering, vol. 6, no. 4, pp. 227-233, 2001.
[35] P. Clemente, G. Nicolosi, and A. Raithel, "Preliminary design of very long-span suspension bridges," Engineering Structures, vol. 22, no. 12, pp. 1699-1706, 2000. 